\title{
Cost of comprehensive patient assistance program in early breast cancer patients
}

\author{
Anne M Stey ${ }^{1,2^{*}}$, Kezhen Fei ${ }^{1}$, Rebeca Franco ${ }^{1}$, Ali Mendelson ${ }^{1}$ and Nina A Bickell ${ }^{1}$
}

\begin{abstract}
Existing comprehensive patient assistance programs can help cancer patients overcome needs and barriers to care: yet the costs of such programs and who utilizes them is not well described. 333 women with primary early stage breast cancer in New York City either chose to attend or abstain from attending one of these programs. We obtained the operating costs of the most utilized patient assistance program. Patients who utilized patient assistance programs were significantly more likely to be English speaking $(p=0.04)$ and have 1.5 years more advanced schooling than non-utilizers ( $p=0.008)$. At the cost of 73 dollars per hour encounters, patients reported benefiting the most from information resources (71\% of patients) followed by emotional support (52\% of patients); $5 \%$ of patients reported getting help with insurance, $5 \%$ with financial assistance, $4 \%$ with help obtaining medication, 2\% with transportation. Existing comprehensive patient assistance programs offer informational, psychological and financial support at low cost. Patients who currently use these programs are English speakers with more education.
\end{abstract}

\section{Introduction}

Disparities in breast cancer survival due to social determinants of health (Weir et al. 2003; Bach et al. 2002; Steinberg 2008; Bickell et al. 2006; Chen et al. 2008 Apr 2; Chu et al. 2003; Ward et al. 2008) may be reduced through timely screening and appropriate treatment. Patient outreach and navigation programs have been shown to improve rates of early detection and follow through to biopsy and treatment (Bickell 2002; Ell et al. 2007; Gabram et al. 2008; Freeman 2006; Battaglia et al. 2007). Such programs are but one type of patient assistance albeit the most researched, and often implemented by academic center clinical trials or through grant funding. Types of patient assitance tested include clinical trials of physical therapy, nurse-led follow-up, group therapy, psycho-social and educational counseling which improve women's quality of life, presumably by improving perceived physical symptoms and psychological functioning (Cruickshank et al. 2008; Gordon et al. 2005; Meneses et al. 2007; Lemieux et al. 2006; Jacobsen et al. 2002; Mandelblatt et al. 2008; Ferrante et al. 2008; David et al. 2007). These programs tend to be heterogeneous, varying

\footnotetext{
* Correspondence: as013j@gmail.com

'Department of Health Policy, Mount Sinai Medical Center, New York, NY 10029, USA

${ }^{2} 10940$ Wilshire Blvd., Suite 710, Los Angeles, CA 90024, USA
}

from those that provide only print materials or peersupport groups to provision of comprehensive care including professional therapists, social work, medical services, educational programs, transportation and even financial support. Programs such as patient navigation, nurse-led and outreach programs, although successful, are costly which is often unsustainable once research is over. Implementing such programs on a large scale requires an investment in infrastructure from an already constrained health system.

The strengths of using existing comprehensive patient assistance programs rather than relying on hospitalbased navigiation include the following: 1) many programs use volunteer-wo/man power of breast cancer survivors who wish to "give back and help" current patients; 2 ) they are already present and integrated into the community, thus do not require the additional investment of hospital-based patient navigator or nurse-led intervention programs; 3) they obviate the need for hospitals to create separate salary lines to support these ancillary services to supplement a health system's strained ability to meet breast cancer patients' needs. Although many community patient assistance programs are available, they are often underutilized, an impetus for the parent randomized control trial from which these data derive (21). We outline the basic cost structure using a 
representative comprehensive volunteer led patient assistance program that was most used by the patients participating in an RCT testing the effectivness of patient assistance. We describe patients' needs and who used patient assistance programs prior to the intervention to randomization.

\section{Methods}

\section{Study protocol}

We defined comprehensive patient assistance programs as programs having professional staffing and volunteer staffing with a not-for-profit status that offer a wide range of services including: outreach screening missions, educational lectures and print material, psychological counseling, peer-support groups and financial aid. The RCT from which data was obtained in this trial recruited English or Spanish speaking women who were treated surgically between October 2006 and July 2010 at eight participating New York City hospitals for new primary early stage breast cancer requiring adjuvant therapy as per national guidelines. Hospitals included four tertiary referral centers and four municipal hospitals. The trial received Institutional Review Board approval at all participating sites; informed consent was obtained from all enrollees.

\section{Survey instrument}

Both baseline and six-month surveys assessed demographic information, health status, use of patient assistance programs as well as the number and type of needs, e.g., informational, psychosocial or practical needs. All surveys were translated to Spanish and validated through back-translation to English to ensure translation accuracy. 333 women were enrolled in the study and completed both baseline and six-month follow-up survey. Based on their needs assessment, women in the trial's intervention arm were referred to existing comprehensive patient assistance programs; those in the control arm received an informational booklet about breast cancer treatment. This analysis reports the cost of attending existing comprehensive patient assistance program and describes who at attended at baseline prior to randomization; it does not assess the efficacy of the randomized trial. We included all women who had attended a patient assistance program from the time of diagnosis to any point prior to enrolling in the trial and categorized them in the patient assistance utilizer group. If they did not use from patient assistance program prior to enrolling, they were categorized in our non-utilizer group. Following baseline survey, participation in the programs was encouraged but not enforced. The two groups of patients who were either attendees or non-utilizers and cross tabulations and one-way ANOVAs were performed with SPSS 20.0.

\section{Cost and statistical analysis}

Need analysis was conducted in an attempt to quantify the degree of perceived lack of social, practical or economic support. Women were separated into $0,1,2$, and 3 needs groups depending on how they answered an initial needs survey which gauged their psychosocial, practical and financial needs (Additional file 1).

Costs were taken from the program costs' perspective and gathered directly from a Breast Health Resource Program, an existing comprehensive patient assistance program in New York City, most frequently used by our study population (Table 1). The cost per hour assumed that each encounter utilized the full range of available services. The total annual expenditure of the program for 2008 was then divided by this number of encounters (6463). All prices were expressed in 2012 dollar and adjusted for Consumer Price Index. As per patient report, each encounter at the program lasted about an hour.

\section{Results}

\section{Study population}

Our study population included 21\% African Americans and $31 \%$ Hispanic women. The majority of women spoke English, but 24\% of women spoke primarily Spanish with $36 \%$ of women from Latin America or the Caribbean (Table 2). Average age was 57 years old. Average income was $\$ 45,000$ per year, $27 \%$ lived in poverty. These women had 14 years on average of years in education; $64 \%$ of women had private health insurance, $29 \%$ of women were solely publically insured (Medicaid/Medicare) and 3\% were uninsured.

The top three accessed Patient Assistance Programs included one local Breast Health Resource Center (19\%), and two national programs the American Cancer Society (15\%) and Cancer Care (13\%). These three programs are comprehensive offering literature, peer-support groups, lecture series, outreach breast cancer screening sessions, social work assistance/insurance application, financial assistance, transportation and medications at no cost to patients (Figure 1). Patients reported benefiting the most from information resources (71\% of patients) followed by emotional support ( $52 \%$ of patients); $5 \%$ of patients reported getting help with insurance, $5 \%$ with financial assistance, $4 \%$ with obtaining medication, $2 \%$ with transportation. The most common source of referral to patient assistance programs was from physicians (50\%), family (9\%) and print material (7\%).

Patients who used the programs at baseline were significantly more likely to be English speaking $(\mathrm{p}=0.04)$ and have 1.5 years more advanced schooling than nonutilizers $(\mathrm{p}=0.008)$. There was a trend for more white patients and those with private insurance to use patient assistance programs. No other differences were noted between the two groups. 
Table 1 Cost per patient encounter derived from the breast health resource center 2007 fiscal year and adjusted for july 2012 inflation

\begin{tabular}{|c|c|}
\hline Description & Cost/e \\
\hline \multicolumn{2}{|l|}{ Patient education program lectures } \\
\hline Mailing/print & $\$ 17.54$ \\
\hline Educational materials & $\$ 3.95$ \\
\hline Food \& beverage & $\$ 10.97$ \\
\hline Auditorium registration & $\$ 4.39$ \\
\hline AV Rental & $\$ 1.32$ \\
\hline \multicolumn{2}{|l|}{ Faculty/program Dev } \\
\hline \multicolumn{2}{|l|}{ Personnel } \\
\hline Salaries W/ Fringe: 4 CSW, 1 admin assist & $\$ 54.88$ \\
\hline \multicolumn{2}{|l|}{ Patient assistance fund } \\
\hline Clinical service (mammo,sono, clinic fee) & $\$ 0.98$ \\
\hline Surgical biopsies/radiologic biopsies & $\$ 0.65$ \\
\hline Post-Op Bras/prosthesis & $\$ 0.33$ \\
\hline Wigs & $\$ 0.08$ \\
\hline Patient transportation & $\$ 0.13$ \\
\hline $\begin{array}{l}\text { Emergency stipend (rent, utilities, food, } \\
\text { childcare, medical insurance payments) }\end{array}$ & $\$ 0.16$ \\
\hline Hospice/comprehensive care & $\$ 0.12$ \\
\hline \multicolumn{2}{|l|}{ Facility costs } \\
\hline Janitorial service & $\$ 1.01$ \\
\hline Electricity & $\$ 0.28$ \\
\hline Storage & $\$ 0.06$ \\
\hline TV/Cable & $\$ 0.05$ \\
\hline Telephone/DSL & $\$ 0.77$ \\
\hline Telephone/computer connection & $\$ 1.55$ \\
\hline Building space rental & $\$ 6.50$ \\
\hline \multicolumn{2}{|l|}{ Administrative and operating costs } \\
\hline Books (medical) & $\$ 0.04$ \\
\hline Catering & $\$ 0.16$ \\
\hline Conference room & $\$ 0.23$ \\
\hline Consultants & $\$ 0.31$ \\
\hline Print shop & $\$ 0.77$ \\
\hline Equipment rental & $\$ 0.33$ \\
\hline Messenger service & $\$ 0.04$ \\
\hline Office supplies & $\$ 0.56$ \\
\hline Photocopy mach supplies & $\$ 0.05$ \\
\hline Postage & $\$ 0.23$ \\
\hline Books/periodicals & $\$ 0.23$ \\
\hline Marketing/website/promo items & $\$ 1.16$ \\
\hline Stationery/brochures & $\$ 0.39$ \\
\hline Subway, taxi, car & $\$ 0.39$ \\
\hline Engineering/sign shop & $\$ 0.16$ \\
\hline Course or conference registration & $\$ 0.19$ \\
\hline
\end{tabular}

Table 1 Cost per patient encounter derived from the breast health resource center 2007 fiscal year and adjusted for july 2012 inflation (Continued)

\begin{tabular}{|c|c|c|}
\hline \multicolumn{2}{|c|}{ Minor office equip/software } & $\$ 0.08$ \\
\hline \multicolumn{2}{|c|}{ Temp help } & $\$ 0.08$ \\
\hline \multicolumn{2}{|c|}{ Total annual cost from third party payer perspective } & $\$ 72.90$ \\
\hline \multicolumn{3}{|c|}{$\begin{array}{l}\text { Jtilization in hours by each needs group and } \\
\text { otal cost }\end{array}$} \\
\hline Need & 8 Hours (SD 5.4 , 95\% Cl 0-16) & $\$ 583.20$ \\
\hline Need & 27 Hours (SD 22.0, 95\% Cl 0-101) & $\$ 1968.30$ \\
\hline Needs & 21 Hours (SD 2.7, 95\% Cl 0-9) & $\$ 1530.90$ \\
\hline Needs & 19 Hours (SD 18.3, 95\% Cl 0-100) & $\$ 1385.10$ \\
\hline
\end{tabular}

Demonstrates the itemized costs of the most frequently accessed volunteer staffed community based comprehensive patient assistance program based on annual budget and total number of visits.

Relationship between quantity of needs, socio-demographic factors \& use of patient assistance programs

Quantity of needs was significantly related to sociodemographic factors (Table 3) with greater number of needs among women who are poor $(<\$ 15,000)$, unmarried, minority, foreign born, Spanish speaking women with low educational attainment (shigh school), had an average of one additional need compared to married, US born, English speaking, more educated white women. 21 patients with no needs spent an average eight hours with a standard deviation of five hours in the patient assistance programs. 21 patients with one need spent an average of 27 hours with a standard deviation of 22 at patient assistance program. 15 patients with two needs spent an average of 21 hours with a standard deviation of 3 hours. 34 patients with three needs spent an average of 19 hours with a standard deviation of 18 hours. There is a trend in increased use of patient assistance programs with needs but due to the large amount of variance means that no significant difference was found in this subsample of patients.

\section{Cost of existing comprehensive patient assistance programs}

The average cost per hour Comprehensive Patient Assistance Programs totaled \$72.90 in the 2012 USD based on the number of one hour encounters in 2007 divided by the annual expenditure (Table 1). The cost of care for each needs group varied according to the quantity of hours spent at the program. No needs group sought support costing an average of $\$ 583$, where as patients with needs used \$1385-1968. The cost for the abstainers was $\$ 1.32$ based on mailing/print material reported cost.

\section{Discussion}

Women with new breast cancer have a range of needs, and existing programs can meet these needs at a 
Table 2 Demographic characteristics

\begin{tabular}{|c|c|c|c|c|}
\hline Variable & Sample (333) & PAP (91) & No PAP (240) & $\begin{array}{l}T \text { or } X \wedge 2 \\
P \text { value }\end{array}$ \\
\hline Age & $61+/-1.2$ & $57+/-2.4$ & $62+/-3.3$ & $1 p=0.323$ \\
\hline Sum of hours & $1.5+/-0.47$ & $4+/-1.6$ & $0.4+/-0.2$ & $14.7 p=000$ \\
\hline Non-white race & $53 \%$ & $49 \%$ & $55 \%$ & $7.6 p=0.1$ \\
\hline Years of Ed & 14 & $15.1+/-0.34$ & $13.6+/-0.3$ & $7.03 p=0.008$ \\
\hline Income $<15$ k & $27 \%$ & $26 \%$ & $28 \%$ & $0.04 p=0.8$ \\
\hline Income $>150 \mathrm{k}$ & $18 \%$ & $14 \%$ & $19 \%$ & $0.9 p=0.34$ \\
\hline Intl birth origin & $41 \%$ & $40 \%$ & $43 \%$ & $0.3 p=0.59$ \\
\hline English & $71 \%$ & $79 \%$ & $67 \%$ & $4.4 p=0.04$ \\
\hline Medicaid & $21 \%$ & $19 \%$ & $22 \%$ & $0.46 p=0.5$ \\
\hline Only public insurance & $6 \%$ & $3 \%$ & $7 \%$ & $1.67 p=0.2$ \\
\hline Medicare & $4 \%$ & $2 \%$ & $5 \%$ & $1.3 p=0.26$ \\
\hline Any public Ins & $31 \%$ & $24 \%$ & $34 \%$ & $3.06 p=0.08$ \\
\hline Married & $49 \%$ & $44 \%$ & $51 \%$ & $1.3 p=0.26$ \\
\hline Utility & 0.61 & 0.61 & 0.61 & $0.52 p=0.47$ \\
\hline Needs & 2 & 2 & 2 & $1.19 p=0.76$ \\
\hline Randomized Rx & $51 \%$ & $56 \%$ & $49 \%$ & $1.4 p=0.27$ \\
\hline
\end{tabular}

Patients who attended programs were more likely to be more educated and speak English than those who did not.

minimal cost. There are few published studies of existing comprehensive patient assistance programs outside the programs based on clinical trials in academic setting (Cohen et al. 2009) (Maisiak et al. 1981; Gilbar \& Groisman 1991; Cella et al. 1993; Edgar et al. 1996). Of the studies that do exist, most are non-standardized surveys reporting on subjective and abstract concepts such as satisfaction and well-being rather than quantitative evaluations of cost and needs (Cella et al. 1993; Edgar et al. 1996).

Patients who attended existing comprehensive patient assistance programs were higher educated English speaking women. The majority of women reported gaining

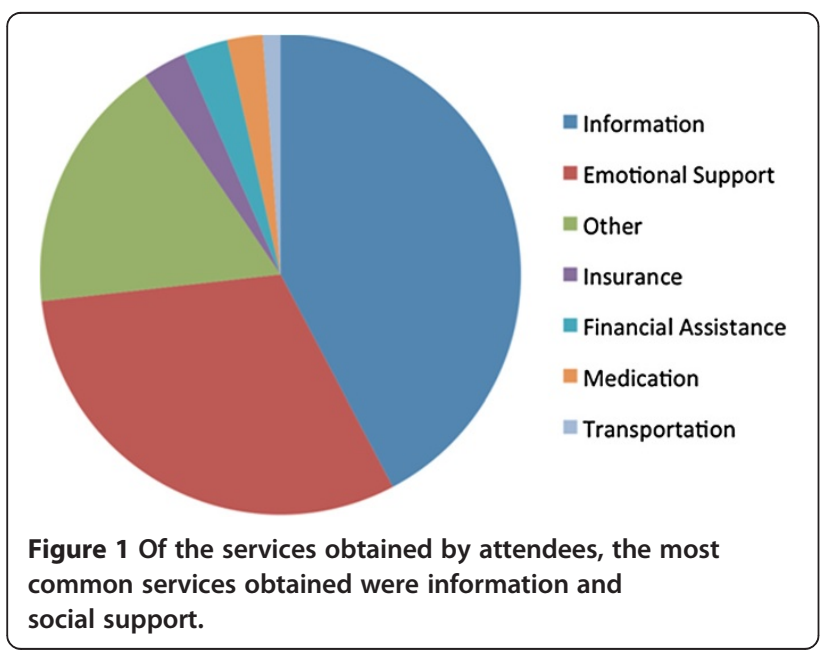

Table 3 Patient number of needs and demographic factors

\begin{tabular}{|c|c|c|}
\hline Demographic factors & $\begin{array}{c}m(S D) \text { number of } \\
\text { needs }(n=333)\end{array}$ & (F) $P$ value \\
\hline Marital Status & & $(9.2) 0.003$ \\
\hline Married & $1.9(1.2)$ & \\
\hline Not Married & $1.5(1.2)$ & \\
\hline Educational Attainment & & (46.2) 0.000 \\
\hline Educated $<12$ yrs & $2.3(1.0)$ & \\
\hline$>$ College & $1.4(1.2)$ & \\
\hline Income & & (60.0) 0.000 \\
\hline Income $>150 \mathrm{~K}$ & $0.7(0.9)$ & \\
\hline Income $<15 \mathrm{~K}$ & $2.3(1.0)$ & \\
\hline Race & & (29.7) 0.000 \\
\hline African American & $1.9(1.0)$ & \\
\hline Latina & $2.5(1.1)$ & \\
\hline White & $1.1(0.9)$ & \\
\hline Foreign born & & (83.1) 0.000 \\
\hline Born abroad & $2.4(1.0)$ & \\
\hline USA born & $1(1.1)$ & \\
\hline Language & & (75.9) 0.000 \\
\hline Spanish speaking & $2.5(0.9)$ & \\
\hline English speaking & $1.4(1.2)$ & \\
\hline Public insurance & & (44.6) 0.000 \\
\hline Medicaid enrollee & $2.3(1.0)$ & \\
\hline No medicaid & $1.3(1.2)$ & \\
\hline
\end{tabular}

Demographic characteristics are associated with number of needs. 
information and emotional support from these groups from access to educational materials, lectures, counseling, at the cost of $\$ 72.9$ per one-hour encounter. Clinical trials have established the effectiveness of the methods such as group counseling, stress management, educational materials, physiotherapy in improving quality of life (Gordon et al. 2005; Lemieux et al. 2006; Jacobsen et al. 2002; Mandelblatt et al. 2008). Similarlarly, patient navigation programs have also been shown to prevent decline in quality of life (Giese-Davis et al. 2006). Comprehensive patient assistance programs such as Breast Health were born out of perceived need in the community (Personal Communication with Andrea Geduld). The integration of survivor volunteers in staffing is not only economically sound but lends the program credibility. An influential source of information comes from peers (Bilodeau and Degner 1996 Lorig et al. 2003; Vasas 2005; Degner et al. 1997; Mullins et al. 2004). Our data demonstrates that information and social support is what patients obtain most commonly from patient assistance programs. Volunteers communication is free of medical jargon and personally relevant from people who are culturally similar (Steinberg et al. 2006). Using lay people to disseminate information may overcome socially derived access barriers and improve quality of life in some cases by improving utilization of health care resources (Battaglia et al. 2007; David et al. 2007; Jo Anne et al. 2002). Patient assistance programs that utilize survivors can potentially become self-sustaining by attracting patients to become volunteer staff members. Despite, fiscal appeal to hospital and insurers and their potential significant impact on women's lives, these programs remain under-utilized (Giese-Davis et al. 2006). According to our data, however, lower educated and non-English speaking women are not taking adequate advantage of these resources.

The quantity of these needs was directly related to demographic factors such as insurance status, income, and educational attainment in this economically and ethnically diverse population. The finding reinforces the validity of self-reported needs as a measure of indigence and our data demonstrate a trend that patients with needs use existing comprehensive patient assistance programs slightly more than those without need. Yet less than one third of all patients utilized these programs.

As a result, we recommend creating a matchmaking system at the time of diagnosis of early stage breast caner that would identify type and number of needs and match patients to relevant comprehensive patient assistance programs like Breast Health Resource Program. This would allow for patients with more needs to be identified and educate them about programs that can provide help.
Limitations include generalizability as NYC costs may over estimate actual cost. Patient surveyed had consented to participate in a clinical trial and may not represent the general population of women with breast cancer due to selection bias. The parent RCT educated patients to enable connection to programs, it did not prevent or strictly enforce attendance. In the end, participants did in effect, self-select whether they attended programs. This study shows who actually used these programs and what we can realistically expect women to receive from it and at what cost if these programs. The effect of patient assistance programs could not be quantified from this baseline survey data. We did not evaluate the degree of services provided and those perceived as most meaningful by patients allow us to gain a better understanding of the structure of these programs as patient resources when there is a known high degree of variability in such programs (Edgar et al. 1996).

\section{Conclusion}

Our data suggest that existing comprehensive patient assistance programs are a low cost way to provide information, emotional support and assistance to obtain insurance, medication and transportation for women with new breast cancer. Such assistance programs present an important opportunity for vulnerable communities in our country and in countries that struggle with limited capital and infrastructure to supplement hospital-based care with community-based support.

I give my written assurance that neither the submitted material nor portions thereof have been published previously or are under consideration for publication elsewhere.

\section{Additional file}

\section{Additional file 1: Needs Assessment Tool.}

\section{Competing interest}

No commercial affiliation or conflict of interest exist with respect to the submitted data.

\section{Authors' contributions}

AS assisted in the design and conducted the statistical analysis, and wrote the manuscript, KF assisted in design and reviewed the manuscript, RF assisted in the design and reviewed the manuscript, All authors read and approved the final manuscript. AM collected data and reviewed the manuscript. NB assisted in the design, assisted in the analysis, and assisted in writing the manuscript. All authors read and approved the final manuscript.

\section{Acknowledgements}

Support for this publication was provided by the Robert Wood Johnson Foundation Clinical Scholars ${ }^{\circledR}$ program and the U.S. Department of Veterans Affairs.

Received: 13 March 2013 Accepted: 15 March 2013 Published: 19 April 2013 


\section{References}

Bach PB, Schrag D, Brawley OW, Galaznik A, Yakren S, Begg CB (2002) Survival of blacks and whites after a cancer diagnosis. JAMA 287(16):2138-9

Battaglia TA, Roloff K, Posner MA, Freund KM (2007 Jan 15) Improving follow-up to abnormal breast cancer screening in an urban population. A patient navigation intervention Cancer 109(2 Suppl):359-67

Bickell NA (2002) Race, ethnicity, and disparities in breast cancer: victories and challenges. Womens Health Issues 12(5):238-51

Bickell NA, Wang JJ, Oluwole S, Schrag D, Godfrey H, Hiotis K, Mendez J, Guth AA (2006 Mar 20) Missed opportunities: racial disparities in adjuvant breast cancer treatment. J Clin Oncol 24(9):1357-62

Bilodeau BA, Degner LF (1996) Information needs, sources of information, and decisional roles in women with breast cancer. Oncol Nurs Forum 23(4):691-6

Cella DF, Sarafian B, Snider PR, Yellen SB, Winicour P (1993) Evaluation of a community-based cancer support group. Psycho-Oncol 2:123-132

Chen AY, Halpern MT, Schrag NM, Stewart A, Leitch M, Ward E (2008 Apr 2) Disparities and trends in sentinel lymph node biopsy among early-stage breast cancer patients (1998-2005). J Natl Cancer Inst 100(7):462-74

Chu KC, Lamar CA, Freeman HP (2003 Jun 1) Racial disparities in breast carcinoma survival rates: seperating factors that affect diagnosis from factors that affect treatment. Cancer 97(11):2853-60

Cohen A, Mohan KN, Fei K, Geduld A, Bicknell N (2009) Are patient assistance programmes able to meet the needs of New York City women with breast cancer? Women's perspectives. European Journal of Cancer Care 18:50-56

Cruickshank S, Kennedy C, Lockhart K, Dosser I, Dallas L (2008) Specialist breast care nurses for supportive care of women with breast cancer. Cochrane Database of Systematic Reviews(1). doi:10.1002/14651858.CD005634.pub2, Art. No.: CD005634

David S, Butler LD, Janine G-D, Cheryl K, Elaine M, Sue DM, Classen CC, Patricia F, Carlson RW, Kraemer HC (2007) Effects of Supportive-Expressive Group Therapy on Survival of Patients With Metastatic Breast Cancer A Randomized Prospective Trial. CANCER 110:5

Degner LF, Kristjanson LJ, Bowman D, Sloan JA, Carriere KC, O'Neil J, Bilodeau B, Watson P, Mueller B (1997 May 14) Information needs and decisional preferences in women with breast cancer. JAMA 277(18):1485-92

Edgar L, Remmer J, Roseberger Z, Rapkin B, Edgar L, Remmer J, Roseberger Z, Rapkin B (1996) An oncology volunteer support organization: the benefits and fit within the health care system. Psycho-Oncol 5:331-341

Ell K, Vourlekis B, Lee P-J, Xie B (2007) Patient navigation and case management following an abnormal mammogram: a randomized clinical trial. Prev Med 44(1):26

Ferrante JM, Chen PH, Kim S (2008 Jan) The effect of patient navigation on time to diagnosis, anxiety, and satisfaction in urban minority women with abnormal mammograms: a randomized controlled trial. J Urban Health 85(1):114-24

Freeman HP (2006 Mar) Patient navigation: a community based strategy to reduce cancer disparities. J Urban Health 83(2):231-43

Gabram SG, Lund MJ, Gardner J, Hatchett N, Bumpers HL, Okoli J, Rizzo M, Johnson BJ, Kirkpatrick GB, Brawley OW (2008 Aug 1) Effects of an outreach and internal navigation program on breast cancer diagnosis in an urban cancer center with a large African-American population. Cancer 113(3):602-7

Giese-Davis J, Bliss-Isberg C, Carson K, Star P, Donaghy J, Cordova MJ, Stevens N, Wittenberg L, Batten C, Spiegel D (2006 Nov) The effect of peer counseling on quality of life following diagnosis of breast cancer: an observational study. Psychooncology 15(11):1014-22

Gilbar O, Groisman L (1991) A training model of a self-help group for patients with cancer of the colon, 7. Psychosoc Oncol 9:57-69

Gordon LG, Scuffham P, Battistutta D, Graves N, Tweeddale M, Newman B (2005 Nov) A cost-effectiveness analysis of two rehabilitation support services for women with breast cancer. Breast Cancer Res Treat 94(2):123-33

Jacobsen PB, Meade CD, Stein KD, Chirikos TN, Small BJ, Ruckdeschel JC (2002 Jun 15) Efficacy and costs of two forms of stress management training for cancer patients undergoing chemotherapy. J Clin Oncol 20(12):2851-62

Jo Anne E, Eugenia E, O'Malley MS, Mary A, Garth R, Linda M, Mathews HF, Lynch KS, Bahjat Q (2002) Increasing Use of Mammography Among Older, Rural African American Women: Results From a Community Trial. American Journal of Public Health 92:4

Lemieux J, Topp A, Chappell H, Ennis M, Goodwin PJ (2006 Nov) Economic analysis of psychosocial group therapy in women with metastatic breast cancer. Breast Cancer Res Treat 100(2):183-90
Lorig KR, Ritter PL, González VM (2003) Hispanic Chronic Disease SelfManagement A Randomized Community-Based Outcome Trial. Nursing Research 52:6

Maisiak R, Cain M, Yarbro CH, Josof L (1981) Evaluation of TOUCH: an oncology self-help group. Oncol Nurs Forum 8:20-25

Mandelblatt JS, Cullen J, Lawrence WF, Stanton AL, Yi B, Kwan L, Ganz PA (2008 Apr 1) Economic evaluation alongside a clinical trial of psycho-educational interventions to improve adjustment to survivorship among patients with breast cancer. J Clin Oncol 26(10):1684-90

Meneses KD, McNees P, Loerzel WW, Su X, Zhang Y, Hassey LA (2007 Sep) Transition from treatment to survivorship: effects of a psychoeducational intervention on quality of life in breast cancer survivors. Oncol Nurs Forum 34(5):1007-16

Mullins CD, Snyder SE, Wang J, Cooke JL, Baquet C (2004 Dec) Economic disparities in treatment costs among ambulatory Medicaid cancer patients. J Natl Med Assoc 96(12):1565-74

Steinberg ML (2008 Jul) Inequity in cancer care: explanations and solutions for disparity. Semin Radiat Oncol 18(3):161-7

Steinberg ML, Fremont A, Khan DC, Huang D, Knapp H, Karaman D, Forge N, Andre K, Chaiken LM, Streeter OE Jr (2006 Dec 1) Lay patient navigator program implementation for equal access to cancer care and clinical trials: essential steps and initial challenges. Cancer 107(11):2669-77

Vasas EB (2005) Examining the margins: a concept analysis of marginalization. ANS Adv Nurs Sci 28(3):194-202

Ward E, Halpern M, Schrag N, Cokkinides V, DeSantis C, Bandi P, Siegel R, Stewart A, Jemal A (2008) Association of insurance with cancer care utilization and outcomes. CA Cancer J Clin 58(1):9-31

Weir HK, Thun MJ, Hankey BF, Ries LA, Howe HL, Wingo PA, Jemal A, Ward E, Anderson RN, Edwards BK (2003) Annual report to the nation on the status of cancer, 1975-2000, featuring the uses of surveillance data for cancer prevention and control. J Natl Cancer Inst 95(17):1276-99, Review

doi:10.1186/2193-1801-2-173

Cite this article as: Stey et al: Cost of comprehensive patient assistance

program in early breast cancer patients. SpringerPlus 2013 2:173.

\section{Submit your manuscript to a SpringerOpen ${ }^{\circ}$ journal and benefit from:}

- Convenient online submission

- Rigorous peer review

- Immediate publication on acceptance

- Open access: articles freely available online

- High visibility within the field

- Retaining the copyright to your article

Submit your next manuscript at $>$ springeropen.com 